\section{Can deception be therapeutic?}

columns
Sir: In their letter, Gralton and Sandford (Psychiatric Bulletin, March 2002, 26, 114) admit withholding information from their patient, suggesting, however, that she 'was not told a lie'.

It was impressed upon many like me in our school-days that to tell less than the truth is to tell a lie. If we, as a profession, reject this version of the matter, might we not reasonably be accused of attempting to deceive ourselves?

Public confidence is paramount, so to defend deception under any circumstances is a risky business. Why take chances?

Larry Culliford Consultant Psychiatrist, South Downs Health NHS Trust, Brighton BN1 3RJ

\section{Abreaction}

Sir: The efficacy of barbiturate-facilitated abreaction in the investigation and treatment of mental disorders has been well documented since 1930, when Bleckwenn carried out his pioneer work. Dysken et al (1979), reviewing the North American literature, cited 52 studies in which the procedure was found to be useful, and there have been no reports of permanent harm. If this valuable technique were to disappear from the therapeutic armamentarium, as suggested by the results of the Wilson survey (Psychiatric Bulletin, February 2002, 26 58-60), it would be a most unfortunate development.

An explanation for the disuse of abreaction may be found in the nature of the procedure as it is usually performed. Psychiatrists are unskilled in parenteral administration and lack confidence in their ability to cope with respiratory depression or laryngospasm. These hazards are eliminated if the necessary drugs are given by mouth.

We have found that the oral administration of up to $300 \mathrm{mg}$ of amobarbital with $80 \mathrm{mg}$ of methylphenidate produces an abreactive state in which the patient can talk freely about sensitive issues and release the corresponding emotions. Addition of the stimulant to the barbiturate combats somnolence and promotes a smooth flow of speech. Employing this method we have enjoyed a number of successes in the treatment of posttraumatic stress disorder.

We believe that abreaction is a unique therapeutic instrument that should be preserved and used more widely than at present.

BLECKWENN,W. J. (1930) Narcosis as therapy in neuropsychiatric conditions. JAMA, 95, 1168-1171.

DYSKEN, M.W., CHANG, S. S., CASPER, R. C., et al (1979) Barbiturate-facilitated interviewing. Biological Psychiatry, 14, 421-432.

R. Denson Psychiatrist, Lakehead Psychiatric Hospital, PO Box 2930, Station P, 580 Algoma Street North, Thunder Bay ON P7B 5G4, Canada

\section{the college}

\section{Neurosurgery for Mental Disorder Report of a Working Group of the Royal College of Psychiatrists' Research Committee}

\section{Council Report CR89} f7.50. 82 pp.

There have been a number of developments in the area of neurosurgery for mental disorder (NMD) in recent years, including marked changes in clinical delivery. This report was produced following extensive collection of evidence from a wide range of individuals and bodies, and a comprehensive review of published data on neurosurgery up to the end of 1999. The working group adopted the following definition of NMD:

'A surgical procedure for the destruction of brain tissue for the purposes of alleviating specific mental disorders carried out by a stereotactic or other method capable of making an accurate placement of the lesion.'

The report discusses the future of NMD services, and concludes that steps should be taken to conserve the current resources within established centres in the UK. It suggests that this could be achieved through the establishment of an independent national advisory committee, which would monitor all aspects of NMD practice. A central task of the national advisory committee would be the establishment of a multi-centre prospective audit, through the deployment of standardised process and outcome measures. It could also be responsible for the development of nationally agreed assessment and treatment protocols, liaising with other international centres and researchers, and publishing an annual report on NMD activity in the UK.

\title{
obituaries
}

\section{Christine Helen Wilson}

Formerly Consultant Psychiatrist Shrewsbury Child Clinic, Shropshire

Christine Helen Wilson, known as Helen, was born in Lincolnshire. She was a vigorous schoolgirl; she cycled regularly and played tennis, netball and hockey. Her medical studies in Newcastle coincided with the onset of severe aggressive rheumatoid arthritis. Helen endeavoured to carry on as usual and played down her disability despite its devastating effect and several surgical interventions. She graduated MBBS (Durham) in 1966.

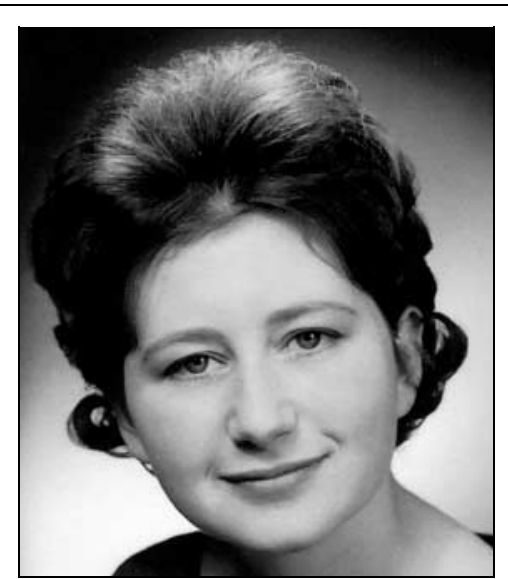

She trained in psychiatry in Newcastle and gained the DPM in 1970 and her MRCPsych in 1972.

Helen joined the West Midlands Training Scheme in Child and Adolescent Psychiatry as a senior registrar in 1972, being based in Shrewsbury and Birmingham. In 1977 Helen took up a consultant child psychiatrist post in Shropshire where, despite her severe disability, she established good relations with patients and their families, and was highly regarded by colleagues at all levels.

After retirement in 1996 she was able to conserve her energy and had several quiet but happy years with her family and 